\title{
SYSTEMATIC IMPLICATIONS OF BUTTERFLY LEG STRUCTURES THAT CLEAN THE ANTENNAE*
}

\author{
BY ROBERT K. ROBbiNS \\ Department of Entomology, NHB STOP 127 \\ Smithsonian Institution, Washington, DC 20560 USA
}

The foreleg tibial epiphyses of Lepidoptera are used to clean the antennae (Jander 1966, ODell et al. 1982 and included references). Among butterflies, the skippers (Hesperiidae) and swallowtails (Papilionidae) possess a tibial epiphysis (Evans 1949, Ehrlich 1958), but other butterfly families do not. The absence of a tibial epiphysis in these families raises the question of how they clean their antennae.

Jander (1966) addressed this question and reported three kinds of cleaning behavior in butterflies. Hesperiids use their foreleg tibial epiphyses to comb antennae. Lycaenids and most nymphalids pull each antenna between a midleg tibia and femur. Satyrine nymphalids clean antennae by sliding each against a midleg tarsus as they walk. Jander did not mention any special structures for cleaning antennae besides the tibial epiphysis.

There is a hypothesized correlation between Jander's behavioral observations and midleg morphology in lycaenids, riodinids, libytheids, and nymphalids. Eliot (1973) reported that there are scale "brushes" on the midleg tibia and femur of virtually all lycaenids, that the function of these brushes is unknown, and that the brushes allow the midleg to be distinguished from the hindleg. Sorensen (1980) hypothesized that the midleg brushes are used by lycaenids to clean the antennae. Scott (1985) accepted this hypothesis, noted that Ehrlich (1958) had discovered a midleg tibial brush in the monarch (Danaus plexippus Linnaeus), a danaiine nymphalid, and reported that similar brushes occur in many riodinids and nymphalids.

The behavior of cleaning the antennae with the legs has been used in determining phylogenetic relations among the butterfly families. Kristensen (1976) proposed that the Nymphalidae (including Libytheidae) and Lycaenidae (including Riodinidae) form a monophyletic lineage, in part because both families use the midleg for

*Manuscript received by the editor June 20, 1989. 
cleaning antennae. He further considered the Pieridae to be the sister group of this lineage, in part because they share loss of the tibial epiphysis. Scott (1985) accepted the former argument, but not the latter.

The purpose of this paper is to detail interfamilial variation in leg morphology and behavior associated with cleaning antennae and to use this information for phylogenetic inference. I examine butterfly leg morphology using a scanning electron microscope (SEM) and summarize this variation in a character matrix. I also record and code variation in antennal cleaning behavior in a taxonomically diverse array of butterflies.

\section{MeThods}

I examined foreleg and midleg tibiae of museum and freshly collected specimens using a scanning electron microscope (SEM). Legs were removed from specimens and soaked in $80 \%$ ethanol for a few seconds until wet, in $10 \%$ potassium hydroxide for approximately 12 hours, in $80 \%$ ethanol for a few minutes, and in $100 \%$ ethanol for at least 10 minutes. I mounted legs on SEM stubs, allowed them to dry, and glued their ends on the stub. In some cases, scales or the epiphysis were removed before mounting. Because leg scale brushes often accumulate positive or negative charges that deflect the electron beam, I often used a $2 \mathrm{kV}$ electron beam.

I first observed the cleaning behavior of butterflies in the field and in cages, but specimens groomed their antennae too infrequently and too rapidly to record behaviors efficiently and accurately. Further, the gypsy moth cleans its antennae during flight (ODell et al. 1982). Therefore, I recorded behavior using a laboratory method outlined below, but report my scanty behavioral observations of specimens cleaning their antennae in the field or in cages because they indicate that my data are not artifacts of this method.

Figs. 1-9. Foreleg tibial epiphyses. 1. Papilio glaucus Linnaeus (Papilionidae) showing position of epiphysis. Scale $1600 \mu$. 2. Enlargement of Fig. 1. Scale $460 \mu$. 3. Female Baronia brevicornis Salvin (Papilionidae). Scale $300 \mu$. 4. Male Parnassius clodius Menetries (Papilionidae). Scale $430 \mu$. 5. Acanthae on epiphysis, female $P$. glaucus. Scale $10 \mu$. 6. Male Erynnis juvenalis Fabricius (Hesperiidae). Scale $150 \mu$. 7. Male Poanes zabulon Boisduval \& Leconte (Hesperiidae). Scale $136 \mu$. 8. Female Pyrrhopyge araxes Hewitson (Hesperiidae). Scale $600 \mu$. 9. Detail of epiphysis groove in Fig. 8. Scale $38 \mu$. 

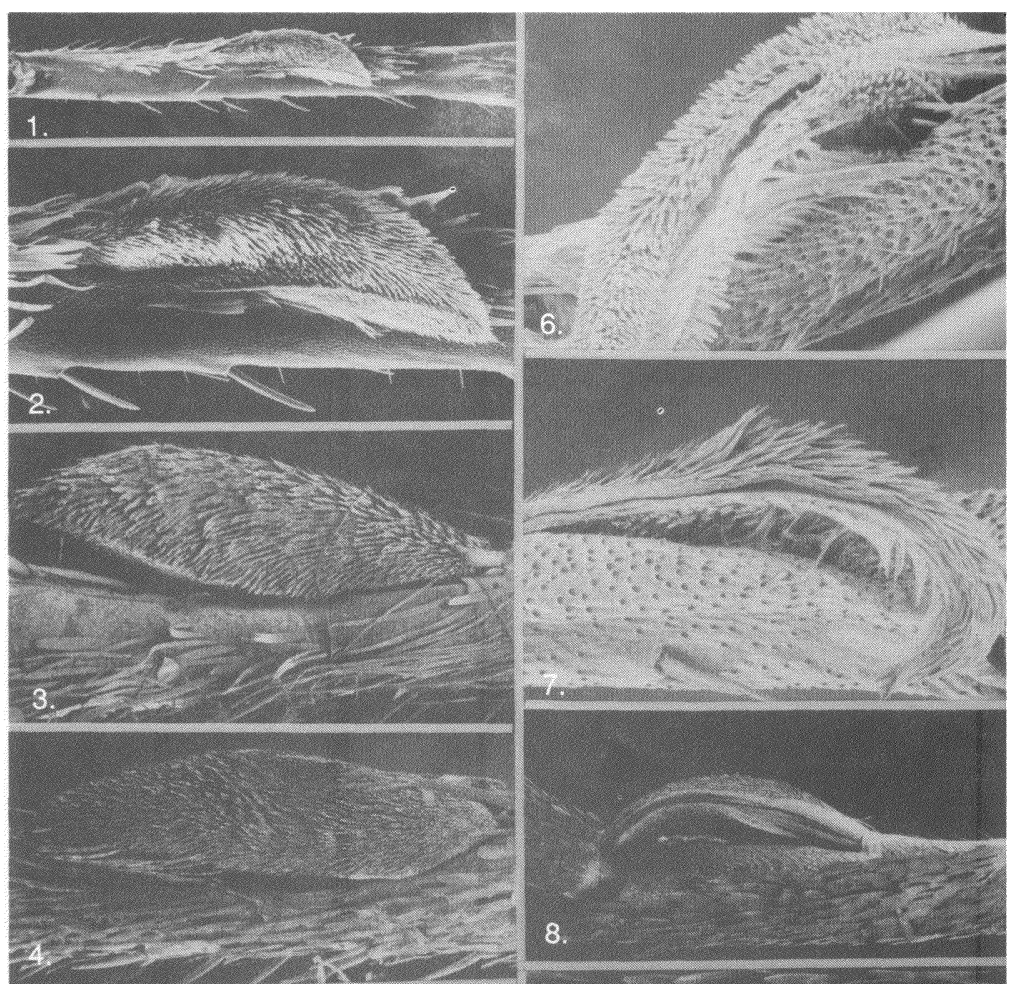

8.
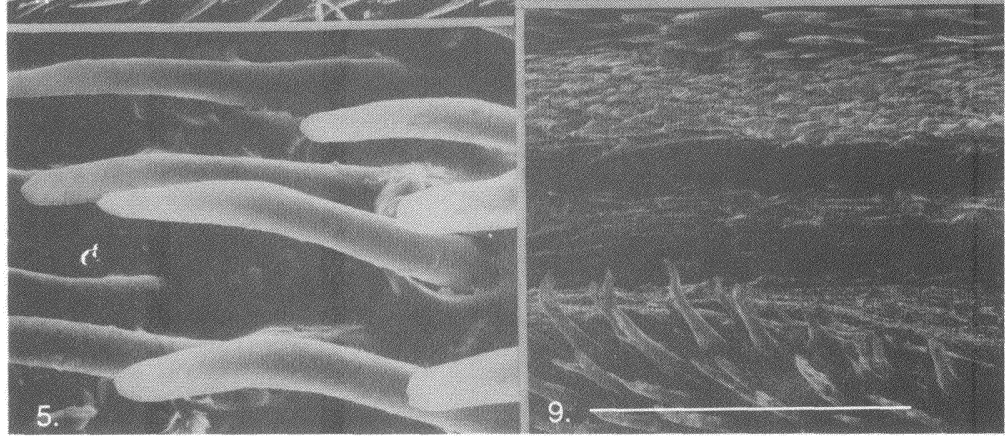
I collected specimens in the field (eastern United States, northern Venezuela), placed them in wire-mesh cages $(27,000 \mathrm{cc}$ or larger, which allowed limited flight), brought them to the lab, and fed them with a dilute solution of honey, salt, and water. Because butterflies rarely cleaned their antennae on the day of capture, I usually waited until the next morning to proceed.

I slightly modified the technique of ODell et al. (1982) for studying the behavior of cleaning the antennae. I anesthetized specimens in a cyanide jar and used a fine brush to coat antennae with the fluorescent powder that ODell et al. used and kindly sent to me. By anesthetizing specimens, I avoided contaminating legs with powder, as frequently occurs when specimens thrash their legs. When powder was no longer visible on the antennae of caged specimens or only a little remained (up to a few hours), I examined legs under a stereomicroscope. If there was no powder, I again coated the antennae, repeating the process just described. If there was powder on the legs, I dry mounted the legs on a labelled microscope slide or put the entire specimen in a labelled glassine envelop. Some tropical taxa are listed by genus because of uncertainty in specific identification. All vouchers are stored at the National Museum of Natural History (Smithsonian Institution).

I describe leg surfaces following Snodgrass (1935); the preaxial surface is anterior and the inner surface ventral. Terminology for cuticular processes follows Richards and Richards (1979).

\section{FORELEG TIBIAL MORPHOLOGY}

There are three types of foreleg tibiae among butterflies; a foreleg tibia (1) with an epiphysis and with a brush of long scales between the epiphysis and tibia (Hesperiidae, Papilionidae), (2) with a brush of long scales but without an epiphysis (some Pieridae), and (3) with

Figs. 10-17. Foreleg tibiae. 10. Male $E$. juvenalis, epiphysis removed to show long scales in trough. Scale $300 \mu$. 11. Small epiphysis of male Megathymus yuccae Boisduval \& Leconte (Hesperiidae). Scale $430 \mu$. 12. Distal foreleg tibia of aberrant male $M$. yuccae with a second epiphysis at tip of the tibia and showing no groove in the epiphysis. Scale $380 \mu$. 13. Small epiphysis of male $M$. ursus Poling showing groove in epiphysis. Scale $250 \mu$. 14. Small epiphysis of male Carterocephalus palaemon Pallus (Hesperiidae). Scale $270 \mu$. 15. Detail of Fig. 14. Scale $86 \mu$. 16. Male Dismorphia melete Johansson (Pieridae) showing scale brush. Scale $300 \mu$. 17. Male D. melete showing scale brush. Scale $270 \mu$. 

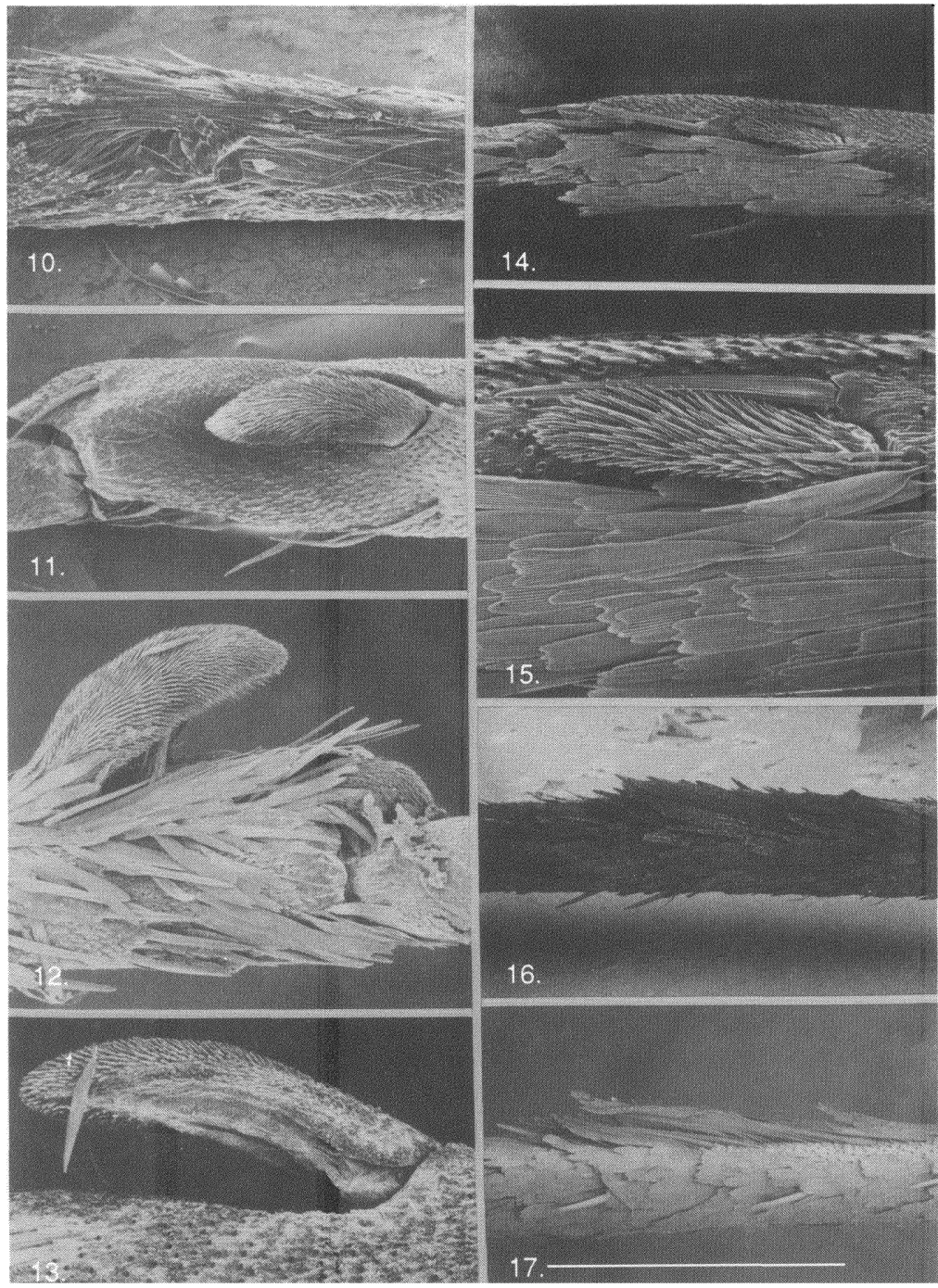
no epiphysis or brush (some Pieridae, Lycaenidae, Riodinidae, Libytheidae, Nymphalidae).

Hesperiidae and Papilionidae have an epiphysis (Bates 1861, Philpott 1924) on the ventral surface of the foreleg tibia (Figs. 1-15) and a brush of long scales between the epiphysis and tibia (Fig. 10). The epiphysis is covered with acanthae on all surfaces except for part of the posterior surface (discussed below). The tibia opposite the basal half of the epiphysis is indented, and this trough is covered with long scales (Fig. 10). As noted in the figure legends, I examined the legs of a diversity of hesperiid and papilionid subfamilies (cf. Scott 1985, J. S. Miller 1987 for taxonomy).

The hesperiid foreleg tibial epiphysis differs from the papilionid epiphysis. The posterior surface of the hesperiid epiphysis has a longitudinal groove devoid of acanthae (Figs. 6-9). This groove is not an artifact of drying because it can be seen with a stereomicroscope in live specimens. I believe that it is the structure that Philpott (1924) referred to as an "aperture." In papilionids, the epiphysis lacks the longitudinal groove that occurs in hesperiids, but some taxa have a narrow ridge lacking acanthae (Figs. 2-3). The epiphysis originates near the middle of the tibia in Papilionidae (Fig. 1) whereas it originates near the distal end and extends beyond the base of the first tarsomere in Hesperiidae (Figs. 6-8).

The hesperiid foreleg tibial epiphysis is small in the Megathymus Scudder group (Figs. 11-13) (often given family or subfamily rank) and the Carterocephalus Lederer group (Figs. 14-15) (Evans 1949, 1955). Evans also reported that it is absent or deciduous in some

Figs. 18-26. Forelegs and midlegs. 18. Foreleg tibia of male Phoebis argante Fabricius (Pieridae) showing scale brush. Scale $500 \mu$. 19. Foreleg tibia of male Anteos chlorinde Godart (Pieridae) showing scale brush. Scale $380 \mu$. 20. Foreleg tibia of male Pseudopontia paradoxa Felder \& Felder (Pieridae) showing lack of a scale brush. Scale $300 \mu$. 21. Foreleg tibia of female Kricogonia castalia Fabricius (PIeridae) showing lack of a scale brush. Scale $500 \mu$. 22. Foreleg tibia of male Catasticta sisamnus Fabricius (Pieridae) showing lack of a scale brush. Scale $600 \mu$. 23. Basal midleg tibia of male Panthiades bathis Fabricius (Lycaenidae) showing scale brush. Scale $270 \mu$. 24. Distal midleg femur of male P. bathis Fabricius showing scale brush. Scale $300 \mu$. 25. Basal midleg tibia of male Lycaena helloides Boisduval (Lycaenidae) with scales removed to show pattern of sockets of scales that form the midleg tibial brush. Basal to the right. Scale $270 \mu$. 26. Basal midleg tibia of male Thisbe irenea Stoll (Riodinidae) showing scale brush. Scale $380 \mu$. 

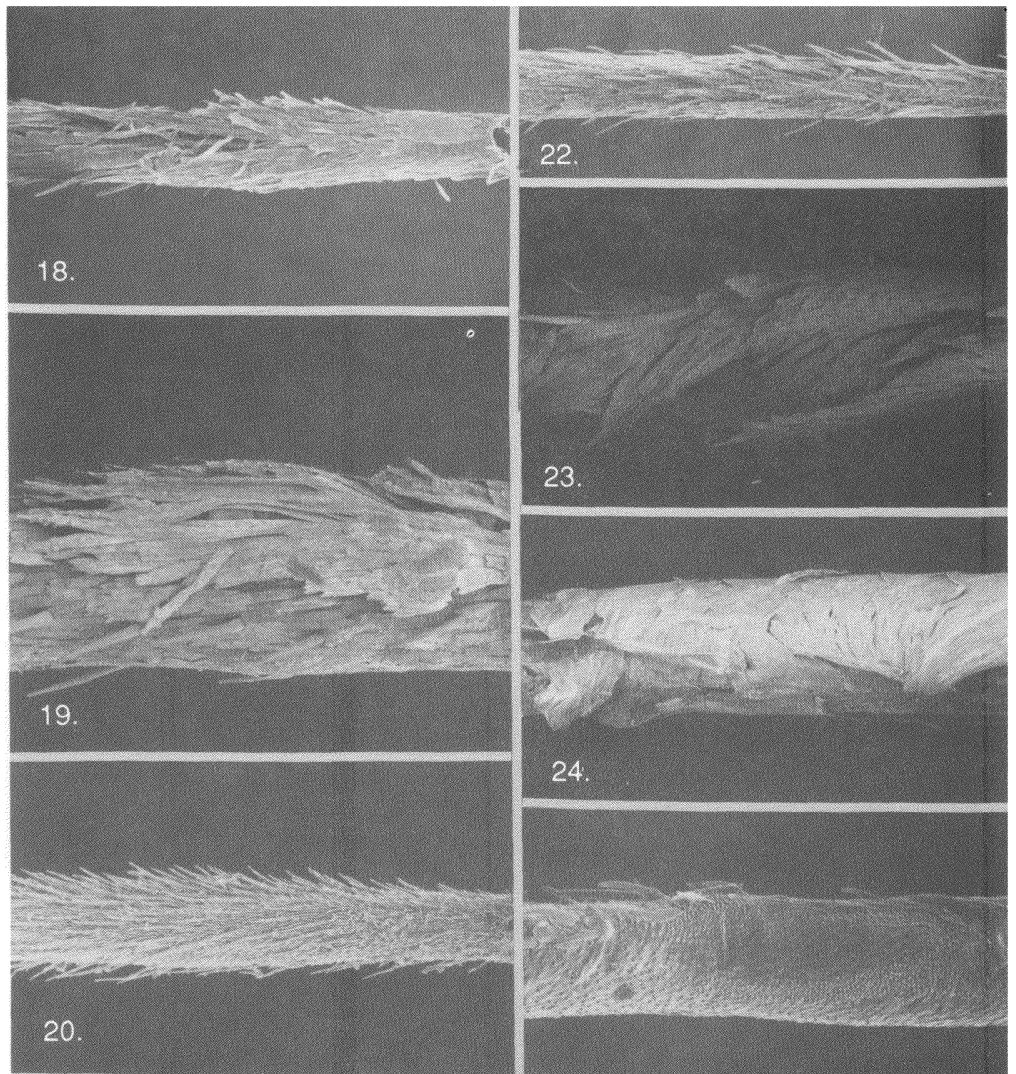

\section{4.}
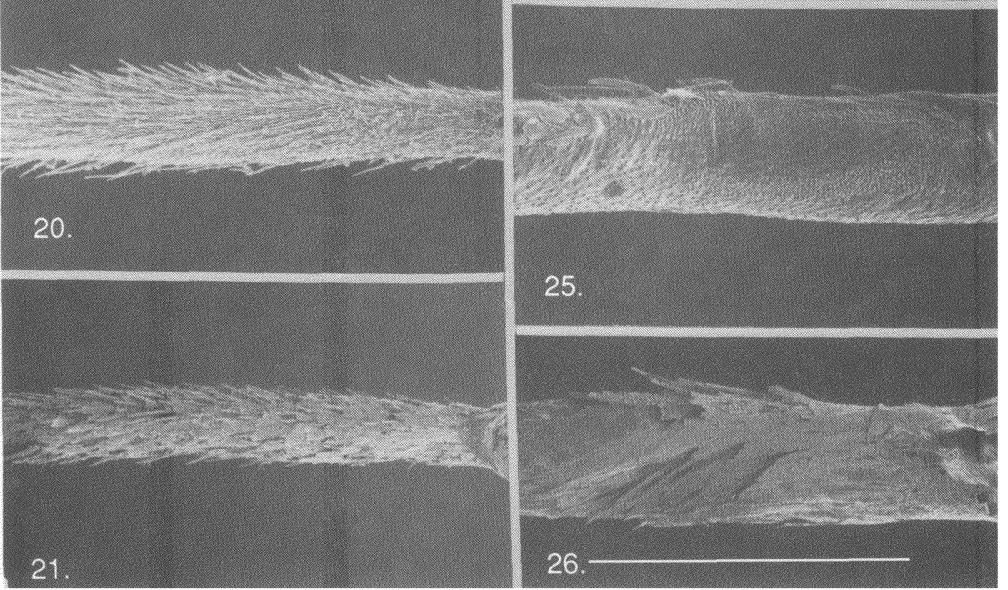
members of the Carterocephalus group, but I have not seen specimens in which the epiphysis is missing. The groove in the epiphysis of Megathymus and Carterocephalus may be present or absent (Figs. 12-13). Although the epiphysis in these groups originates towards the distal end of the tibia, as in other Hesperiidae, it does not extend beyond the base of the first tarsomere (Figs. 11, 14). One aberrant specimen of Megathymus yuccae Boisduval \& Leconte had two tibial epiphyses (Fig. 12).

The pierid foreleg tibia lacks an epiphysis, but some taxa have a brush of long scales on the ventral surface. The scale brush is welldeveloped in some genera of Dismorphiinae (Dismorphia Hübner, Pseudopieris Godman \& Salvin) (Figs. 16-17) and Coliadinae (Anteos Hübner, Phoebis Hübner, Colias Fabricius, Catopsila Hübner) (Figs. 18-19). It is absent or poorly developed in Pseudopontiinae (Pseudopontia Plötz) (Fig. 20), Dismorphiinae (Leptidia Dalman), Coliadinae (Eurema Hübner, Gonepteryx Leach, Nathalis Boisduval, Kricogonia Reakirt) (Fig. 21), and Pierinae (Catasticta Butler, Archonias Hübner, Pieris Schrank, Pontia Fabricius, Ascia Scopoli, Anthocharis Boisduval) (Fig. 22). I had great difficulty determining whether the scale brush is present or absent in some coliadine genera, which is why I describe it as "absent or poorly developed." The scales of the brush are probably homologous with the scales found between the tibia and epiphysis in Hesperiidae and Papilionidae, but unlike these families, pierid tibiae are not indented.

Character 1. Foreleg tibia (A) with epiphysis that lacks a longitudinal groove on posterior surface, (B) with epiphysis that has a longitudinal groove on posterior surface, $(C)$ without an epiphysis. Because most Lepidoptera other than butterflies have a tibial epiphysis without a longitudinal groove (Philpott 1924), I consider state $\mathrm{A}$ to be primitive for the butterflies. The distribution of this character is summarized in Table 1.

Character 2. Foreleg tibia (A) with a brush of long scales on ventral surface, (B) without a brush of long scales on ventral surface. Since both states occur in Pieridae, this family is coded as dimorphic. 


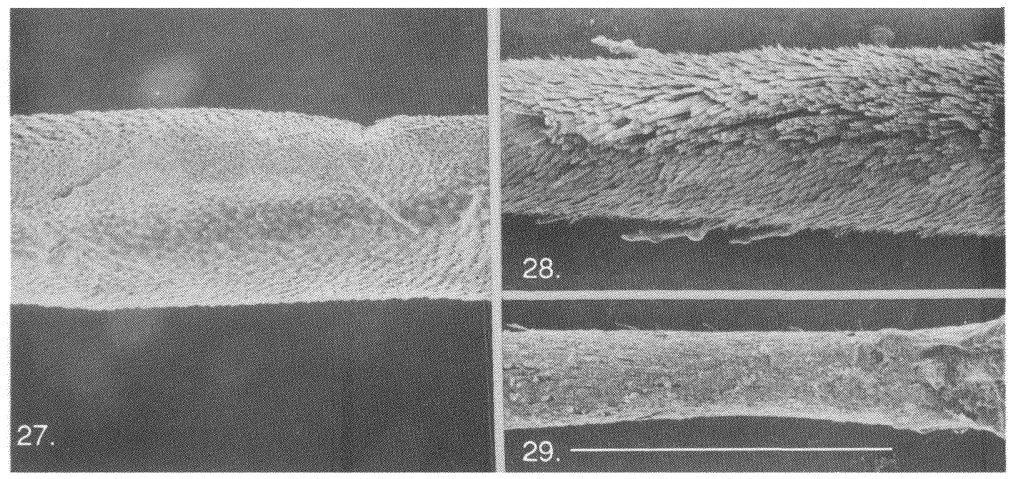

Figs. 27-29. Midleg tibiae. 27. Female Libythea bachmanii Kirtland (Libytheidae) showing pattern of scale brush sockets. Scale $250 \mu$. 28. Female Danaus plexippus Linnaeus (Nymphalidae) showing scale brush. Scale $500 \mu$. 29. Female Ancyluris inca Saunders (Riodinidae) showing lack of a scale brush. Scale $500 \mu$.

\section{Midleg Tibial MoRPHOLOGY}

There is a brush of scales on the basal half of the midleg tibia in some butterflies. In most lycaenids, long scales form the sides of a trough on the basal midleg tibia (Fig. 23), and there are other long scales on the distal part of the midleg femur (Fig. 24). The brush scales are more dense than other scales, as indicated by the density of scale sockets on denuded legs. (Fig. 25). Similar scale brushes occur in some Riodinidae (Fig. 26), Libytheidae (Fig. 27), and Nymphalidae (Fig. 28).

Expression of the midleg tibial scale brush varies within families. The brush is weakly developed to absent in Pentilini (Lycaenidae) (Eliot 1973), many Riodinidae (Fig. 29), and some Nymphalidae, particularly Satyrinae and Ithomiinae. In Danaus plexippus, the ventral side of the trough is absent (Fig. 28). Midleg tibial scale brushes are unknown in Hesperiidae, Papilionidae, and Pieridae.

Character 3. Midleg tibia (A) without a scale brush, (B) with a scale brush. Although expression of the midleg tibial brush is variable in Lycaenidae, Riodinidae, and Nymphalidae, I code them with state B (Table 1) because they are the only lepidopteran families 
(along with Libytheidae), so far as I am aware, in which such a scale brush occurs. Absence of the brush is primitive for the butterflies.

\section{Behavioral Results}

Hesperiidae. Almost every specimen that survived to the second day after capture had powder, which had been applied to the antennae, concentrated on the foreleg tibial epiphysis, and to a lesser extent, on the long scales under the epiphysis. Specimens examined: Male Poanes zabulon Boisduval \& Leconte, two male Erynnis icelus Scudder \& Burgess, male E. juvenalis Fabricius, female Heliopetes Billberg, Urbanus Hübner (sex undetermined), and male Epargyreus clarus Cramer. I observed a caged male E. juvenalis clean its antennae with its forelegs while landed, but could not distinguish the foreleg part that was used.

Papilionidae. A female Eurytides marcellus Cramer and male Papilio troilus Linnaeus had powder concentrated on the tibial epiphysis.

Pieridae. In contrast to the preceeding two families, I found powder on the legs of less than $20 \%$ of experimental pierid specimens. Specimens with powder on their legs included those with a foreleg tibial brush-male Dismorphia Hübner and two female Phoebis sennae Linnaeus - and without a brush - two male and female Eurema Hübner (two species) and female Ascia monuste Linnaeus. In each instance, the powder was scattered over the foreleg tarsus and tibia, and was not restricted to the tibial brush, when present. Jander (1966) did not observe Pieris grooming their antennae and neither did I (more than 20 specimens).

Lycaenidae. Most specimens that survived to the second day after capture had powder concentrated on the midleg tibial brushes and, less frequently, on the midleg femoral brushes. I recorded this result with male Satyrium calanus Hübner, three female "Thecla" iambe Godman \& Salvin, female Calycopis Scudder, three males and female Mitoura gryneus Hübner (Theclinae), female Hemiargus Hübner, and two female Everes comyntas Godart (Polyommatinae). I twice observed lycaenids in the field clean their antennae between their basal midleg tibia and distal midleg femur while landed: male Feniseca tarquinius Fabricius (Miletenae) in Washington, DC, USA, Aug. 1984; male Calycopis (Theclinae) on Taboga Island, Panama, Sep. 1984. 
Riodinidae. Although seven Venezuelan riodinids of four species were tested, I found no powder on their legs. All had midleg tibial brushes.

Libytheidae. I coated the antennae of two males and a female of Libythea bachmani Kirtland, and in each case, found powder concentrated on the midleg tibial brush.

Nymphalidae. I observed powder on the midleg tibial brushes of those species in which the brush was well-developed. Specimens scored included two female Danaus plexippus, male Morpho Fabricius, male and female Asterocampa celtis Boisduval \& Leconte, female Hamadryas februa Hübner, female Dynamine Hübner, female Pyrrhogyra Hübner, male Adelpha Hübner, male Siproeta epaphus Latreille, and male Polygonia comma Harris.

Some apparently unrelated nymphalids lack or have very poorly developed midleg tibial brushes, such as Satyrinae, Ithomiinae, genus Actinote Hübner, and the species Phyciodes tharos Drury. I found powder on the legs of specimens in these taxa only rarely, and when I did, it was scattered over the midleg tibia and midleg tarsus (two male Megisto cymela Cramer, male and female Actinote, and four specimens of Venezuelan Ithomiinae).

Character 4. Antennae are cleaned by moving them (A) between the foreleg tibia and epiphysis, (B) against the foreleg tibia and tarsus, (C) between the basal midleg tibia and distal midleg femur, (D) against the midleg tarsus and tibia. Since character state A is widespread among non-butterfly Lepidoptera, I suggest that it is the primitive state for the butterflies. The other states are unordered, and their distribution is summarized in Table 1.

Table 1. Character matrix for the butterfly families and four characters associated with cleaning antennae. The characters and their states are described in the text. Character state $A$ is the primitive state for each, but no order is implied for the other states in characters 1 and 4.

\begin{tabular}{lcccc}
\hline Family & \multicolumn{4}{c}{ Characters } \\
& 1 & 2 & 3 & 4 \\
\hline Hesperiidae & B & A & A & A \\
Papilionidae & A & A & A & A \\
Pieridae & C & A,B & A & B \\
Lycaenidae & C & B & B & C \\
Riodinidae & C & B & B & $?$ \\
Libytheidae & C & B & B & C \\
Nymphalidae & C & B & B & C,D \\
\hline
\end{tabular}




\section{Discussion}

The longitudinal groove on the posterior surface of the foreleg tibial epiphysis appears to be a previously unrecognized autapomorphy of the hesperiidae. It occurs in the major hesperiid subfamilies and is absent only in some of those species with a small epiphysis. Although Philpott (1924) discovered this structure, it has not been used in systematics to characterize the Hesperiidae (Evans 1949, Kristensen 1976, Scott 1985).

The pierid foreleg tibial brush has not been previously noted, so far as I am aware (e.g., Klots 1933, Ehrlich 1958), but its presence appears to be homoplastic. It may be present or absent in the presumably monophyletic pierid subfamilies Dismorphiinae and Coliadinae (cf. Ehrlich 1958 for taxonomy). It may, however, provide phylogenetic information within these subfamilies.

Leg brushes function to clean antennae in some taxa, but not in others. My behavioral results confirm the hypothesis that the lycaenid midleg tibial brush is used to groom the antennae (Sorensen 1980) and that the same is true in the Libytheidae and Nymphalidae (Scott 1985). In those Pieridae with a foreleg tibial brush, however, the brush is not used to clean antennae.

My results are consistent with Jander's (1966) excellent observations with a minor exception. She found that satyrine nymphalids clean their antennae by sliding them along the midleg tarsus while walking, but my data indicate that nymphalids lacking midleg tibial brushes-including satyrines-rub their antennae against both the midleg tibia and midleg tarsus.

Ehrlich (1958), Kuznetsov (1967), Kristensen (1976), and Scott (1985) proposed different phylogenies to the butterfly families. The distribution (Table 1) of the first character (presence of a foreleg tibial epiphysis) is consistent with Kristensen's phylogeny, but the epiphysis would have to have been lost or gained twice on the other phylogenies. As mentioned, the second character (presence of a foreleg tibial brush) is homoplastic within the Pieridae and will provide useful phylogenetic information for a family level phylogeny only after its primitive state within the Pieridae is resolved. The third and fourth characters are consistent with all the phylogenies except Ehrlich's and support monophyly of the group, Lycaenidae + Riodinidae + Libytheidae + Nymphalidae. 


\section{SUMMARY}

Butterflies in different families clean their antennae with their legs in different ways. Hesperiidae and Papilionidae use their foreleg tibial epiphysis to clean antennae, but a groove in the posterior epiphysis of hesperiids appears to be an autapomorphy for the family. Many Pieridae have a foreleg tibial scale brush, but rub their antennae against the foreleg tibia and foreleg tarsus generally, not specifically on the scale brush. Most Lycaenidae, Riodinidae, Libytheidae, and Nymphalidae have a midleg tibial-and sometimes midleg femoral-scale brush that is used to clean the antennae. Some Nymphalidae lack the brush and rub their antennae against the midleg tarsus and midleg tibia.

\section{ACKNOWLEDGMENTS}

I thank Tom ODell for sending me the powder used in the behavioral experiments. I thank Brian Kahn for technical assistance with the SEM and, in particular, for finding realistic solutions to charging problems. I thank the late Francisco Fernandez-Yepez for allowing me to work at Rancho Grande, Venezuela, where some of the field work for this paper was done. I am most grateful to David Adamski, Niels Kristensen, and Thomas ODell for many constructive criticisms that greatly improved the paper.

\section{Literature Cited}

Bates, H. W. 1861. Contributions to an insect fauna of the Amazon Valley.Lepidoptera-Papilionidae. J. Entomol. 1: 218-245.

EHRLICH, P. R. 1958. The comparative morphology, phylogeny and higher classification of the butterflies (Lepidoptera: Papilioniodea). Univ. Kansas Sci. Bull. 39: 305-370.

Eliot, J. N. 1973. The higher classification of the Lycaenidae (Lepidoptera): a tentative arrangement. Bull. Brit. Mus. (Nat. Hist.) Entomol., 28: 371-505.

Evans, W. H. 1949. A catalogue of the Hesperiidae from Europe, Asia and Australia in the British Museum (Natural History). British Museum, London, 502 pp.

Evans, W. H. 1955. A catalogue of the American Hesperiidae indicating the classification and nomenclature adopted in the British Museum (Natural History). Part IV. Groups H-P, Hesperiinae and Megathyminae. British Museum, London, 499 pp., pls. 54-88.

JANDER, U. 1966. Untersuchungen zur Stammesgeschichte von Putzbewegungen von Tracheaten. Z. Tierpsychol. 23: 799-844. 
KLots, A. B. 1933. A generic revision of the Pieridae (Lepidoptera). Entom. Am. 12 (new series): 139-242.

Kristensen, N. P. 1976. Remarks on the family-level phylogeny of butterflies (Insecta, Lepidoptera, Rhopalocera). Z. zool. Syst. Evolut.-forsch. 14: 25-33.

KuZnetsov, N. Y. 1967. Fauna of Russia and adjacent countries, Lepidoptera. Vol. .1, Introduction. Israel Program for Scientific Translations (published for the U.S. Department of Agriculture and the National Science Foundation), Jerusalem, $305 \mathrm{pp}$.

Miller, J. S. 1987. Phylogenetic studies in the Papilioninae (Lepidoptera: Papilionidae). Bull. Amer. Mus. Nat. Hist. 186: 365-512.

ODell, T. M., K. S. Shields, V. C. Mastro, and T. J. Kring. $1982 . \quad$ The epiphysis of the gypsy moth, Lymantria dispar (Lepidoptera: Lymantriidae): structure and function. Can. Entomol. 114: 751-761.

Philpott, A. 1924. The tibial strigil of the Lepidoptera. Trans. N. Zealand Inst. 55: 215-224.

Richards, A. G., P. A. Richards. 1979. The cuticular protuberances of insects. Int. J. Insect Morphol. \& Embryol. 8: 143-157.

ScotT, J. A. 1985. The phylogeny of butterflies (Papilionoidea and Hesperioidea). J. Res. Lepid. 23: 241-281.

SNODGRASs, R. E. 1935. Principles of insect morphology. McGraw-Hill Book Co., New York, 667 pp.

SORENSEN, J. T. 1980. An integumental anatomy for the butterfly Glaucopsyche lydamus (Lepidoptera: Lycaenidae): a morphological terminology and homology. Zool. J. Linnean Soc. 70: 55-101. 

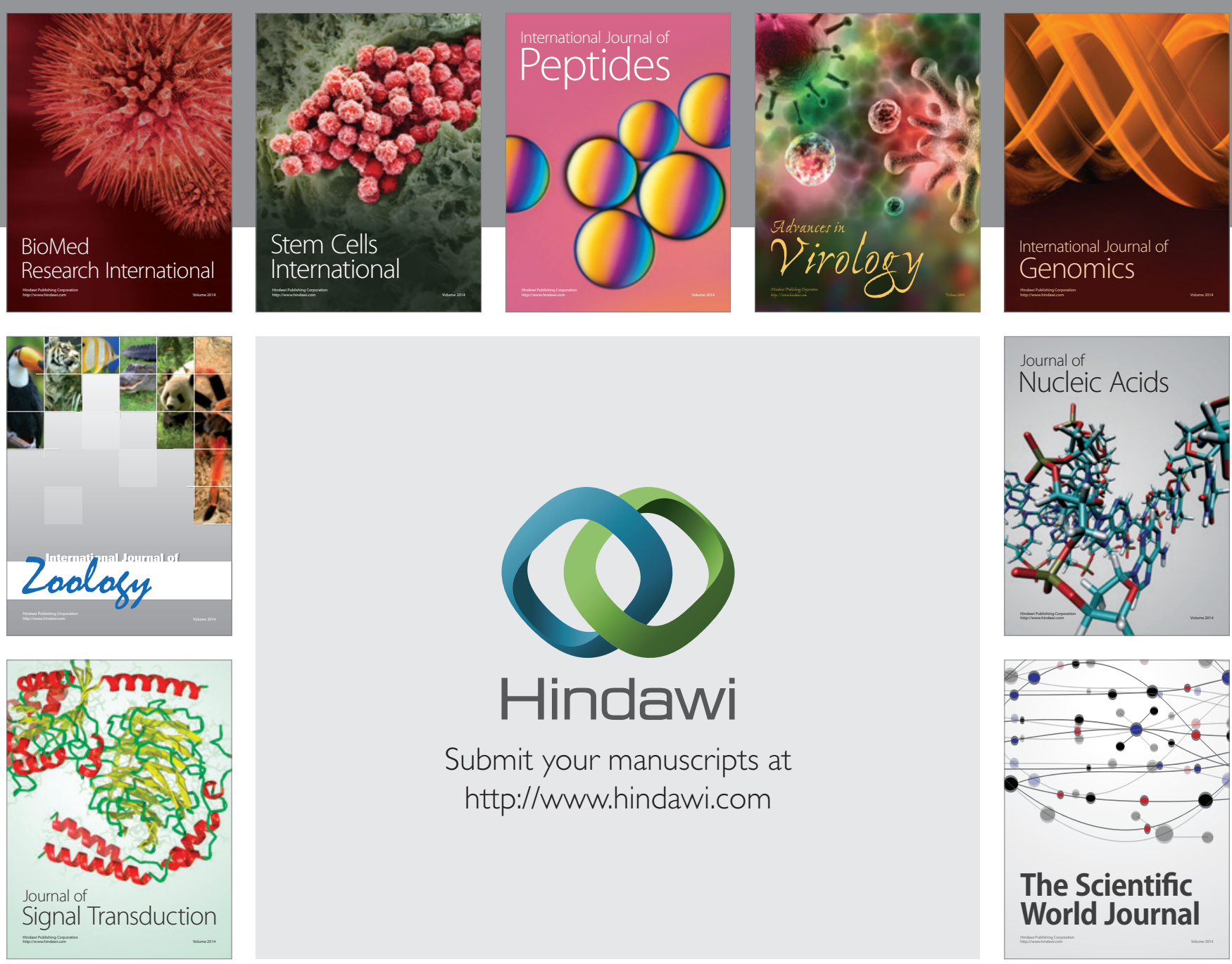

Submit your manuscripts at

http://www.hindawi.com
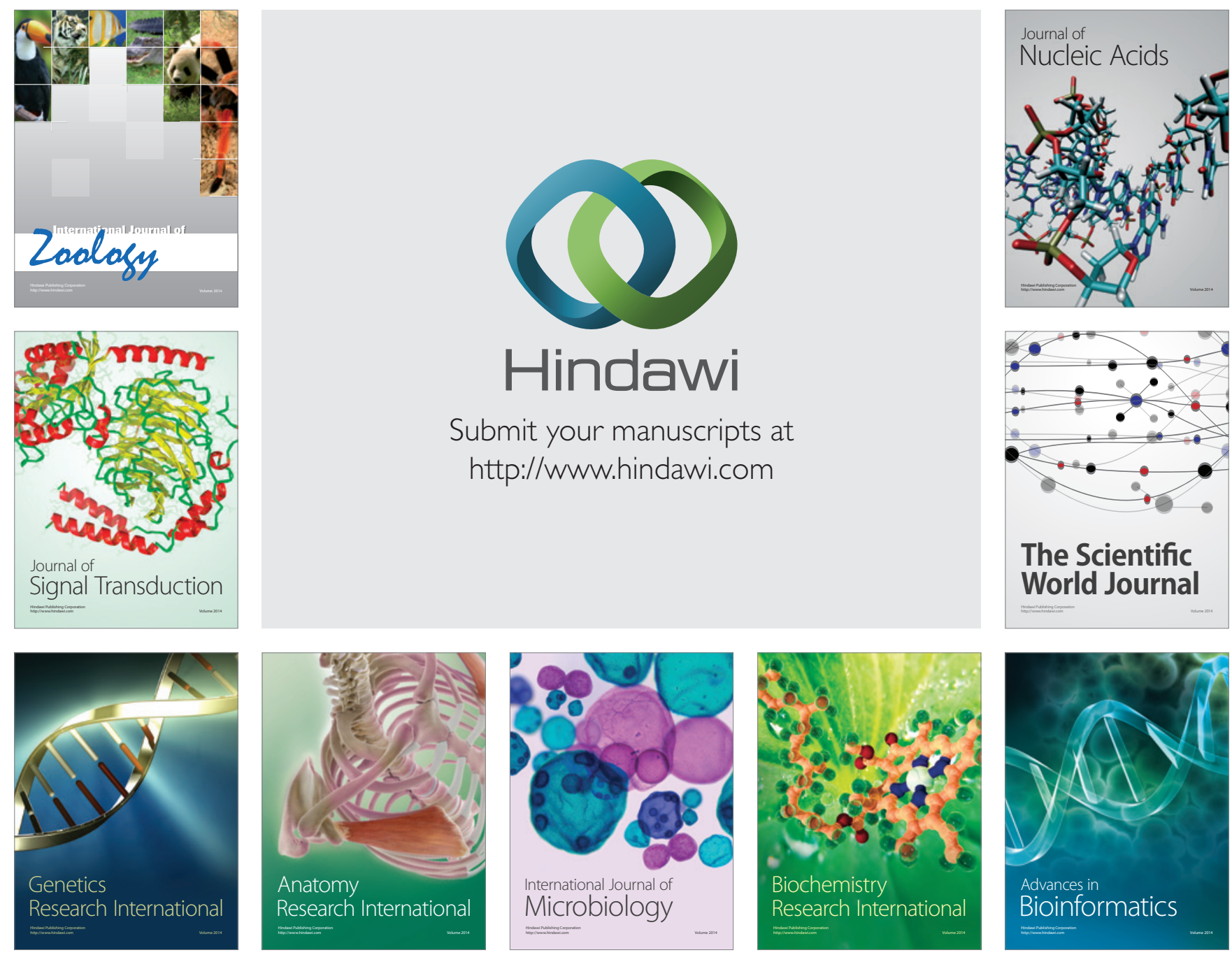

The Scientific World Journal
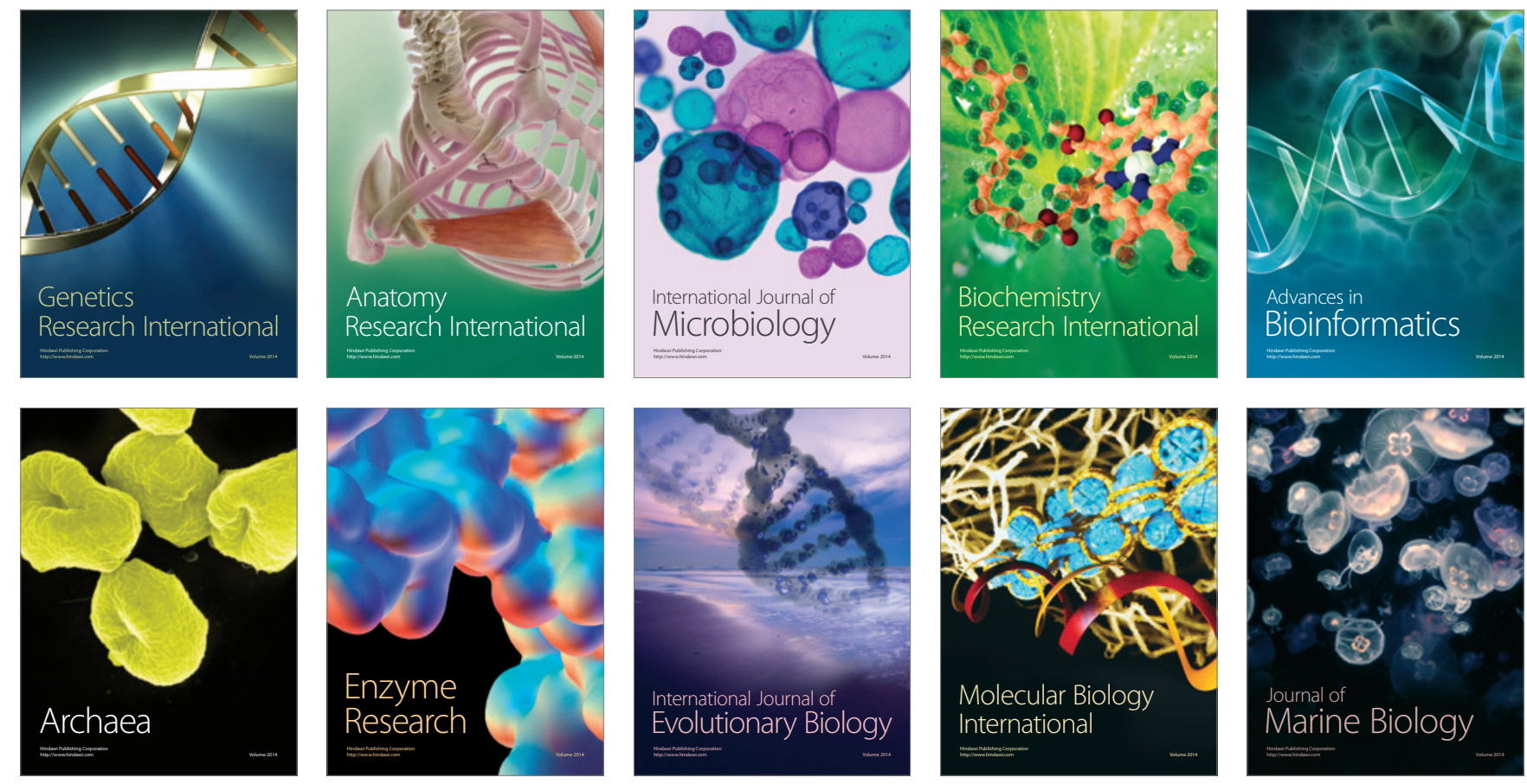